\title{
Biopoder, psicopoder y gramatización ${ }^{*}$
}

\author{
Bernard Stiegler \\ Traducción del francés al español de Luis Alfonso Paláu-Castaño \\ Universidad Nacional de Colombia, sede Medellín, Colombia \\ lapalau@gmail.com
}

\section{De la producción al consumo}

Los trabajos de Michel Foucault sobre la biopolítica y sobre las técnicas de sí constituyen, en su conjunto, una reflexión sobre la sexualidad y una discusión con el psicoanálisis. Es este objetivo el que conecta a estas problemáticas; no es solamente la técnica. O más bien: la técnica es la manera específica que Foucault tiene de plantear la cuestión de la sexualidad; piensa tras la estela de Freud y de Lacan lo que distingue instinto, pulsión y deseo, pero rebasa el examen de estas cuestiones exclusivamente a título de la constitución de la prohibición, la ley y la represión (Foucault, 2007, pp. 29-34) (como se lo trata igualmente por tradición en etnología [Stiegler, 2006; Foucault, 1999, pp. 235-254]). Por esto, Foucault se da como programa pensar el poder no a partir de la ley, sino a partir de sus tecnologías. Lo que hace que el instinto pase al estadio de la pulsión es el poder como tecnología, por donde Foucault introduce la técnica en la constitución del deseo.

Sin embargo, algo permanece oscuro en cuanto a la situación de esta cuestión de la tecnología; Foucault nunca interroga aquí el carácter tecnológico de la ley misma, y ello por la misma razón que hace que él no explore la cuestión específica de la escuela entre las instituciones disciplinarias. De la misma manera como la disciplina escolar es precisamente ante todo, en el skholeion, la disciplina que constituye el saber racional y por ello una introducción a la épiméleia, a la mélétè y a las técnicas de sí como diversos tipos de disciplinas, es decir, de formación de la atención, pero que comparten precisamente con la ley el hecho de ser técnicas de la letra; el derecho es lo que literaliza y gramatiza las existencias al tramar

Cómo citar: Stiegler, B. (2021). Biopoder, psicopoder y gramatización (L. Paláu, trad.). Ciencias Sociales y Educación, 10(20), 263-284. https://doi.org/10.22395/csye.v10n20a12

Traducción realizada por Luis Alfonso Paláu-Castaño del texto de Stiegler (2008, cap. 8, pp. 301-325).

Agradecemos la editorial Flammarion permitir el acceso del libro en francés para la versión en español del capítulo 7. Se conserva la versión editorial en francés.

Recibido: 6 de febrero de 2021.

Aprobado: 20 de febrero de 2021. 
allí nuevas reglas en los procesos de transindividuación y seguir dispositivos intergeneracionales perfectamente homogéneos con los circuitos de transindividuación por donde se forman las disciplinas del pensamiento racional, con las cuales el derecho forma en esto "regularidades discursivas"1.

Hay algo de común a las tecnologías de poder y a la ley, que es precisamente la técnica hipomnésica que constituye la base de las psicotécnicas que forman la épiméleia. Ahora bien, estas psicotécnicas de sí son esas a las que la escuela introduce desde la antigüedad, pasando por la iglesia hasta la escuela laica, para un sí mismo que, en la modernidad, se vuelve así un nosotros; el nosotros de la mayoridad (liberado del dogma religioso) que piensan Kant y Condorcet. No preguntarse por la duplicidad esencial del pharmakon que aquí aparece es cerrarse a la posibilidad de pensar los otros tipos de pharmaka que constituyen las psicotecnologías movilizadas por el cine y por la televisión, y sus efectos sobre la individuación psíquica y colectiva, es decir, sobre sí mismo.

No cabe duda de que, al filo de este recorrido, Foucault busca precisamente conjugar todos esos temas en el sentido de una cuestión de sí que tiende hacia la individuación en tanto que ella es indisociablemente psíquica y colectiva (individuación que él llama una subjetivación): "Me intereso cada vez más en la interacción que se opera entre sí y los otros" (Foucault, 1990a).

Esta interacción, que está en el corazón de la subjetivación, constituye la cuestión de la gubernamentalidad. Pero en el momento en que él muere, esta conjugación aún no había tenido lugar. Creo que esto tiene que ver, por una parte, con que, desde Las palabras y las cosas (Foucault, 1968), existe una ausencia de problematización de la cuestión de la letra y de la república de las letras, es decir, desde los efectos de la imprenta en el Renacimiento y en la época clásica hasta la Ilustración y posteriormente.

Por esto, cuando hace aparecer ¿Qué es la ilustración?, un año después de la publicación de La escritura de sí, donde la escritura aparece como la condición de la constitución de sí tal como se proyecta siempre ya hacia los otros ${ }^{2}$ por ese vínculo que constituye el pharmakon (que también puede desliar y envenenar al sí mismo, pero este tema no es abordado por La escritura de sí), Foucault (1983) está de alguna manera impedido por sus trabajos anteriores a remarcar el papel que juega la técnica de la escritura en la formación del concepto kantiano de mayoridad. Y, a fin de cuentas, no plantea en ninguna parte la cuestión farmacológica que, sin embargo, es esencial a toda terapéutica, medicalización y a toda

"Las regularidades discursivas" es el título de la segunda parte de La Arqueología del saber (Foucault, 1970a, pp. 33-127).

2 En particular en tanto que arte epistolario, cfr. Foucault (1983, pp. 3-23). 
cuestión del cuidado y de la épiméleia: no hay medicina sin esta farmacopea ${ }^{3}$, lo que, hechas todas las cuentas, quizás sea la verdadera cuestión del poder.

Pero se me objetará - en cuanto al papel de la escritura en la formación de la mayoridad que sería la Aufklärung según Kant- que este último no parece conceder importancia a lo que escribe sobre la escritura y la lectura, como si él no hubiera leído lo que ha escrito en tanto sabio delante de nosotros que lo leemos. Ahora bien, Foucault subraya tan precisamente la importancia de la letra y de la escritura que uno no puede dejar de decirse que aquí la inatención de Foucault a esta cuestión en Kant (a la cual el propio Kant está extrañamente tan poco atento) procede de un mecanismo que se parece mucho a una denegación. Esta denegación es la metafísica misma, como estadio organológico y sucesión de épocas de disimulación del organon (es decir del pharmakon) por el organon (por el pharmakon), lo que se traduce en Kant por una teoría del esquematismo ${ }^{4}$ sobre la que es preciso preguntarse hasta qué punto pesa sobre la arqueología foucaultiana.

En Las mallas del poder, Foucault (1999) se inscribe por el sendero de Marx cuando este plantea (igualmente contra el juridismo en materia de teoría del poder) que no hay un poder, sino muchos: el taller, el ejército, la esclavitud, la servidumbre, etc. (p. 239). Es necesario hablar de los poderes y "tratar de localizarlos en sus especificidades históricas y geográficas" (Foucault, 1999, p. 240).

Ahora bien, me parece precisamente que el biopoder, que el propio Foucault se dedicó a describir histórica y geográficamente (y tan poderosamente localizándolo en Europa), ya no es lo que trama nuestra época. En este sentido, este concepto no puede dar cuenta (sin ser renovado) de la especificidad del psicopoder psicotecnológico, de la nueva situación del biopoder que de ello resulta ni, por tanto, de la "biopolítica" tal como ella se vuelve una psicopolítica que ya no tiene que ver con los Estados nacionales (y con instituciones de programas), sino con potencias económicas desterritorializadas (y con industrias de programas) que constituyen nuevas relaciones discursivas y no discursivas, es decir, nuevos dispositivos.

Con las tecnologías de poder nace la actuación. Su objetivo, dice Foucault (1999), ya no es "impedir" (como lo hace el poder de la prohibición que prescribe la ley, y a partir del cual el psicoanálisis piensa la transformación del instinto en pulsión, ella misma ligada por la libido en tanto que dispositivo de censura), sino

¿Cómo pensar la medicina moderna sin pensar el papel que en ella toma el medicamento, y cómo no pensar el biopoder médico como nacimiento de la industria farmacéutica? Ahora bien, Foucault (1970b) no le concede ningún sitio a estas cuestiones en Naissance de la clinique: Une archeologie du regard medical.

4 Es la tesis que he sostenido en La técnica y el tiempo 3 (Stiegler, 2005, pp. 72 y ss.). 
"optimizar" (p. 241) (y esto es también lo que claramente describe Weber como proceso de racionalización y desencantamiento $)^{5}$. Por tanto, sería igualmente necesario interrogar aquí todo lo que - por ejemplo, en la ley que instituye la instrucción pública obligatoria- obliga precisamente en tanto abre un derecho de saber y, en esto, no se reduce a un impedimento. Por el contrario, instaura una potencia positiva de sublimación como disciplina de transindividuación que instituye políticamente la mayoridad que constituía la esencia de la Aufklärung.

La actuación sistemática y tecnológicamente buscada con la ciencia del poder, que viene luego del Renacimiento, conduce a las sociedades disciplinarias como dispositivos organológicos. Es, por ejemplo, el fusil que, como órgano técnico ${ }^{6}$, impone la formación de un nuevo cuerpo de ejército, es decir, de una organización social disciplinaria que requiere el desarrollo de competencias por las cuales los individuos (soldados en el ejército, productores en la fábrica, niños en la escuela, etc.) adquieren un valor por la interiorización en su organización psíquica y somática del funcionamiento del órgano técnico, que es también su individualización en y por la "máquina de producción".

Ahora bien, esta individualización (que es una particularización) conduce a la desindividuación (como lo habrá mostrado Marx, y sobre todo Simondon [2008, pp. 131-137] a partir de Marx). No se trata de una interiorización individualizadora, ni la disciplina de esta tecnicidad es la constitución de un sí mismo; al tender hacia la automatización, ella expropia los individuos de todo saber. Las tecnologías de poder conducen necesariamente (como gramatización) a la exteriorización de los saberes en las máquinas sin otra interiorización que aquella por la cual el individuo le "sirve" al sistema (el cañón, la máquina, el aparato). Al menos en esta lógica del pharmakon que es el biopoder, se trata en verdad, por la "disciplina", de liquidar la atención y de formar un cuerpo social de menor "de edad" explotable como un puro recurso viviente de producción, lo que Marx llamaba precisamente la fuerza de trabajo. Además, esta lógica se extiende en el siglo XX al consumidor; pero esto es precisamente lo que la teoría del biopoder no permite pensar.

Con esta tecnología política que es la disciplina, es necesario -en el ejército, la fábrica y a escuela, pero también por la administración que forma en

La proximidad de los análisis de Vigilar y castigar con los de Weber es a veces sorprendente.

En Las mallas del poder, Foucault (1999) escribe que es menester "hacer no solamente la historia de las técnicas industriales, sino también la de las técnicas políticas". Esto significa que la organología es de las organizaciones sociales como de los artefactos materiales que llaman las técnicas; y esto es lo que no comprendió Deleuze (Stiegler, 2004, p. 24). Pues el fusil como órgano técnico es lo que requiere una organización social compatible con su uso y capaz de asegurar la formación de los individuos y su administración racional según sus competencias (su individuación, precisamente) que se trata pues de evaluar. 
esto una policía en el sentido amplio-, "controlar en el cuerpo social hasta los elementos más tenues, por los cuales llegamos a alcanzar los átomos sociales mismos, es decir los individuos" (Foucault, 1999, p. 244). Esto se hace para explotar mejor el valor de la población que así se ha formado, lo que confiere un papel fundamental, funcional y nuevo al aprendizaje y, más generalmente, a la educación. El ejército, la fábrica y la escuela operan de la misma manera, según Foucault, para poner en su sitio una tecnología individualizadora -es decir, desindividuante- al servicio de una política "que apunta en el fondo a los individuos hasta en sus cuerpos, en sus comportamientos [...] hasta anatomizarlos" (Foucault, 1999, p. 246).

Esta tecnología del poder, que es una "anatomía política", no es, sin embargo, el biopoder propiamente hablando. Pues este no se ejerce sobre sujetos, sino sobre poblaciones "de seres vivos atravesados, comandados, regidos por procesos, por leyes biológicas" (Foucault, 1999, p. 246) por el dominio de las cuales se trata de utilizar esta población como "máquina para producir".

Pero, precisamente, la cuestión del biopoder no es tanto hoy la de "utilizar la población" para la producción como la de constituirla en mercados para el consumo. Y es aquí donde los análisis de Foucault no pueden sernos suficientes. Lo que él describe - que es a fin de cuentas la génesis del Estado que se encamina hacia la revolución industrial con la conquista del poder por la burguesía - establece las condiciones de formación del capitalismo típico del siglo XIX (tal como lo habría descrito Marx) y cuya primera preocupación es la producción. Pero el siglo XX encuentra cuestiones completamente distintas.

La cuestión del siglo XX es la revolución de los modos de existencia humanos que deben volverse modos de consumo al mismo tiempo que liquidan las mundologías en lo que se vuelve una economía industrial de servicios cuya base son las industrias de programas ${ }^{7}$. Es lo que conduce a la destrucción de los medios asociados, es decir, de los medios simbólicos, que son reemplazados por medios disociados (Stiegler, 2006b, pp. 50-55; Stiegler, 2006a, p. 29), es decir, medios cibernéticos. Y la ciencia de todo esto no es tanto la cibernética misma -(como lo creía Heidegger [Stiegler, 2006b, p. 41]) y que en realidad es un estadio de la gramatización-, sino el mercadeo que prescribe esta farmacología, y que hace de los niños prescriptores de sus padres, y de esos padres, niños grandes ${ }^{8}$. Así, el mercadeo es una prescripción contra todo sistema de cuidado $\mathrm{y}$, en particular, contra todos los circuitos intergeneracionales.

Sobre este punto, cfr. Stigler (2006 b, p. 41)

$8 \quad$ "Nuestro papel no es ayudar a nuestros niños a seguir siendo niños, ni siquiera a volverse grandes niños, sino ayudarlos a volverse adultos, a volverse ciudadanos. Todos somos educadores" (Sarkozy, 2007). 
Esta escena por donde el biopoder de Estado se vuelve el psicopoder del mercado no se juega tanto en Europa como en los Estados Unidos. Ella entra a Europa después de la Segunda Guerra Mundial y la invade literalmente a partir de los años 1970, poco después de 1968, en el momento en que sobreviene la crisis petrolera y la conmoción del Estado-providencia. Nosotros mismos, en el siglo XXI, seamos lo que seamos en todo el mundo industrializado, vivimos frente al embrollo colosal que habría inducido esta incuria, de donde ha desaparecido toda biopolítica (al ser esta siempre en Foucault el hecho de Estado), pero donde apareció que las psicotecnologías de este psicopoder, que arrasa la salud mental y física de las poblaciones, y en particular de los niños, en el porvenir de la economía mundial, conforman sistema con una forma de financiación ruinosa.

Esta destruye la inversión y la reemplaza por la especulación y, por ello, juega sistemáticamente al corto término contra el largo plazo. El verano de 2007 habría mostrado que esta incuria está de aquí en adelante en el principio mismo de la economía mundial, y eso habría dado una primera idea, aún confusa y débil, de los inmensos peligros que ella le hace correr a la humanidad planetarizada (Aglieta, 2007).

\section{La otra disciplina; poder de escritura y escritura del saber}

En una conferencia pronunciada en 1982 en la universidad de Vermont ${ }^{9}$ (un año antes de la aparición de La Escritura de sí), Foucault (1988) se refiere a menudo a Von Justi: "La policía gobierna, no por la ley sino interviniendo de manera específica, permanente y positiva en la conducta de los individuos" (p. 9).

Ahora bien, en la actualidad es mucho más el mercado que el Estado el que así interviene, es decir, muy precisamente "de manera específica, permanente y positiva en la conducta de los individuos". Y en 1982 ya era evidente el caso. Pero me parece que Foucault no vio nada de esto. En desquite, esto será algo que subrayará Deleuze en 1990.

Es en la obra de Von Justi donde aparece el concepto de población y, con él, a partir de esos pensadores de la razón de Estado luego de la policía y de la "ciencia del Estado" que son Botero, Turquet y Lamare, se localizan los conceptos del biopoder. En el espíritu de Von Justi,

los elementos físicos o económicos del Estado (tomados en su totalidad) constituyen un medio del que la población es tributaria y que, recíprocamente, depende de la población. [...] el Estado debe ante todo velar sobre los hombres en tanto que población. Ejerce su poder sobre los seres vivos en tanto que seres vivos, y su política es, por consiguiente, necesariamente una biopolítica. (Foucault, 1988, p. 10)

Será publicada en 1988 con el título la Tecnología política de los individuos, en su original como Technologies of the Self. 
Sin embargo (quizás objetaría aquí Kant), este viviente es noético; está dotado de una conciencia y es susceptible de pasar de la minoridad a esa mayoridad sin la cual ninguna política digna de ese nombre es verdaderamente posible. La grandeza de Federico II habría estado en no haber reducido la política prusiana a su policía, aun cuando Prusia era precisamente el país de esta "ciencia del Estado" ${ }^{10}$. Incluso si tiene que obedecer y observar una disciplina en este sentido, un buen prusiano, dice Kant (agradeciéndole a Federico II por haber hecho posible "el siglo de Federico", y más allá de ese siglo, y de Prusia y del buen prusiano, al ser humano en su mayoría de edad que adviene cosmopolíticamente con la aufklärung y lo define por eso mismo), también debe criticar, es decir, observar (como se observa una regla) y no solamente conservar.

Observar significa aquí examinar esa otra disciplina, que es la formación de la mayoridad, como esa suerte de atención que se llama consciencia racional y que se forma al inscribirse en el espacio del "poder de escritura" del que Foucault lee su aparición en Von Justi, Bentham, etc. como siendo también y aún y siempre un saber de escritura por donde el espacio político se abre como espacio crítico de la escritura ante el público que lee. Que el poder de escritura se despliegue como sofística o individualización disciplinaria puede, ciertamente, enmascarar que haya un saber de escritura, y que es algo adulto; pero esto no se les puede ocultar sino a los menores. La escritura es ese espacio crítico que es también, evidentemente y en el mismo golpe, dúplice, es decir, farmacológico y crítica también en este sentido.

Tal es la condición, dice Kant, de la escritura del saber, es decir, de la persecución de su individuación. En un lenguaje más reciente, le objetaríamos a Von Justi que el ser farmaconoético simboliza porque desea y que solo él desea y transforma sus pulsiones. Por ese hecho (el hecho por donde se forma un derecho) ya no son simplemente instintos en tanto que simboliza noéticamente; noesis que es también una voluntad de saber (de acceder a las consistencias como objetos ideales). Que el biopoder busque reducir el ser farmaconoético a la sola condición de su subsistencia, a lo que Marx llama la renovación de su fuerza de trabajo, es un hecho. Pero es también el objeto de una lucha que tiene efectos políticos, es decir, institucionales y, por ello, materiales, especialmente como instrucción pública. Pero Foucault, a pesar de ser muy atento a las instituciones materiales (como vamos a verlo), borra extrañamente de sus descripciones históricas.

Esta lucha plantea que hay, además del biopoder, un psicopoder, es decir, un poder sobre las almas del que la filosofía (dirigiéndose a Hipias, Alcibíades, Menón, Fedro y tantos otros jóvenes atenienses) hace la crítica desde que ella

Al respecto, se sugiere consultar "Omnes et singulatim", hacia una crítica de la razón política de Foucault (1990b). 
se opone a la práctica sofística del pharmakon logográfico para transformar ese psicopoder en un noopoder (lo que Platón llama la dialéctica y la anamnesis). Es lo que conduce por un proceso histórico y organológico a lo que Kant, Mendelssohn y la aufklärung llaman la mayoridad (o la bildung) de los que leen y escriben. Por esto Condorcet pone a la escuela en el corazón de todo combate social ${ }^{11}$; es aquella que Ferry concreta socialmente en Francia un poco menos de un siglo después de la respuesta de Kant a la pregunta de la Berlinische Monatsschrift.

Cuando Deleuze propone que las sociedades disciplinarias le han cedido su lugar a las sociedades de control, esto significa que de ahí en adelante el psicopoder asegura el control del comportamiento, la ciencia de la policía y del Estado al haberle cedido la plaza al apoderamiento, el mercadeo, la disciplina y la modulación. El mercadeo se presenta ante todo como tecnología de las public relations con Edward Bernays (2007), luego con Esneest Dichter y Louis Cheskin. El objetivo ya no es formar y explotar productores, sino controlar comportamientos de consumidores por medio del desarrollo de psicotecnologías que tienden a liquidar la noopolítica propuesta desde Ferry por las instituciones de programas. Pues la sociedad disciplinaria industrial encuentra en esos momentos su límite: la superproducción, primero en la época de Bernays (los años 1920 y 1930), y luego después de la Segunda Guerra Mundial.

\section{Del Estado al mercado}

Un artículo de la agencia de publicidad MacGraw-Hill publicado por la revista Advertising Age el 24 de octubre de 1955 se dirige así a los productores estadounidenses:

En tanto que nación, somos ya tan ricos que los consumidores no tienen ninguna necesidad de comprar una gran parte —quizás el $40 \%$ - de nuestra producción, y esta necesidad disminuirá progresivamente en el curso de los próximos años. Ahora bien, si los consumidores escogen no comprar una gran parte de la producción, no está lejana una fuerte depresión económica. (Packard, 1958, p. 23)

Esta amenaza es, de hecho, una consecuencia concreta de la baja tendencial de la tasa de ganancia — que tiene como corolario el aumento del desempleo y la pauperización - contra la cual el capitalismo lucha para no dejar de intensificar la innovación, pero que engendra inevitablemente excedentes de producción y una obsolescencia crónica de los productos con respecto a la cual es necesario sostener cada vez más artificialmente el consumo:

Y luego de un amplio pensamiento de la disciplina matemática de la que Catherine Kintlzer (1987) recordaba el rigor en plenos años foucaultianos. 
Desde 1950, en momentos en que la superproducción amenazaba numerosos frentes, los preocupaciones de los dirigentes de las sociedades industriales sufrieron una modificación fundamental. La producción pasó para ellos a segundo plano. En lugar de pensar en fabricar, pensaran en vender. (Packard, 1958, p. 24)

La cuestión no es ya, entonces, y en la actualidad mucho menos aún, controlar la población como máquina de producción, sino más bien como máquina de consumo; y el envite ya no es el biopoder, sino el psicopoder como control y fabricación de motivaciones: "En las conferencias de industriales y de comerciantes, se habló de 'revolución del mercado', y se reflexionó mucho sobre los medios para 'estimular' a los compradores creándoles necesidades cuya existencia ellos ignoraban" (Packard, 1958, p. 24).

En este contexto, se desarrolla en los Estados Unidos la Investigación de los móviles, de la que Ernest Dichter es el principal representante. Plantea en principio que es necesario encontrar "los medios de pre-acondicionar al cliente para comprar [los productos] 'grabándole las características en el cerebro'" (Packard, 1958, p. 28).

Es así como se emprende el proceso que conducirá a la destrucción del aparato psíquico juvenil y a la liquidación de las relaciones intergeneracionales. Para ello, tras las huellas de los primeros trabajos de Bernays (pero también de la cibernética aplicada a los condicionamientos de los equipamientos de las fortalezas volantes durante la Segunda Guerra Mundial) Dichter y Cheskin ponen el psicoanálisis al servicio del análisis sistemático de los mercados. Es así como invitan a los industriales a distinguir entre tres dimensiones en el aparato psíquico de sus clientes: i) la consciencia, que no es manipulable; ii) el preconsciente, que los investigadores norteamericanos llaman con más gusto subconsciente; y iii) el inconsciente.

Vance Packard (1958) puede desde entonces escribir que "la exploración de nuestras actitudes con respecto a los productos, a los niveles dos y tres, es ahora conocida, en tanto que ciencia nueva, bajo el nombre de Análisis o de Investigación de móviles" (p. 28).

Vimos al comienzo de esta obra cómo el mercadeo trata, a principios del siglo XXI, de tomar el control del aparato psíquico y social de los niños desde su más tierna infancia. Destruye los circuitos intergeneracionales donde se forman los circuitos de reproducción biológica de las poblaciones, los circuitos de la sexualidad donde se cruzan las cuestiones biopolíticas y las de las técnicas de sí, que son a la vez somáticas y psíquicas.

Hacia la cuestión de la sexualidad entendida así ampliamente, es decir, como socialización del deseo y socialización como deseo que dispone del principio del 
placer y el principio de realidad converge todo el trabajo de Foucault. Así, él escribe en 1976 que

el sexo está en la bisagra entre la anatomo-política y la bio-política, en la encrucijada entre las disciplinas y las regulaciones, y en esta función es como ha llegado a ser, al final del siglo XIX, una pieza política de primera magnitud para hacer de la sociedad una máquina de producción. (Foucault, 1999, p. 247)

Pero además de que acá la regulación es entendida en un sentido muy restrictivo, que no tiene en cuenta el sentido que toma esta palabra con Keynes (precisamente frente a los peligros de la superproducción que esta problemática del biopoder parece ignorar totalmente), la sexualidad que Foucault busca pensar a partir del deseo se volverá precisamente, como energía libidinal, el factor de base de la economía consumista; se tratará entonces de hacer de la sociedad una máquina de consumo (las máquinas industriales están ahí para lo que tiene que ver con la producción, lo que engendra la baja de la tasa de ganancia y el aumento del desempleo, ante los cuales el capitalismo reacciona intensificando la carrera de la innovación y la obsolescencia y se vuelve así la cuestión primordial el consumo y el control psíquico) para construir una nueva economía libidinal.

Sin embargo, la cuestión fundamental actualmente se ha vuelto la autodestrucción de esta economía libidinal capitalista y consumista, porque una economía libidinal durable supone siempre la identificación primaria y la identificación secundaria psíquica y colectiva (Stiegler, 2006), es decir, la formación de un superyó y la capacidad de sublimación. Ahora bien, en el momento mismo en que Packard describe la "RM", Marcuse muestra que el desarrollo del mercadeo televisivo, como industria de programas comportamentales, engendra a la vez lo que él llama un superyó automático y un proceso de desublimación (Marcuse, 2002, p. 89; Stiegler, 2006a) .

Y esto es perfectamente congruente con el hecho de que si el biopoder es lo que conduce a "reemplazar el derecho por la administración" (Foucault, 1988, p. 11), la educación nacional es un caso insigne de una tal administración como institución de programas comportamentales. Foucault los describe como disciplinarios en tanto conducen a la formación de una atención que tiende hacia una mayoridad por la adquisición de las disciplinas que forman el saber. Con ello, sin embargo, esta administración, que se ha vuelto la educación, procede de un derecho a la instrucción pública que es también una obligación tanto para los ciudadanos como para el Estado.

Este derecho, la obligación mutua (como sistema de cuidado) y la administración como gubernamentalidad de la épiméleia de sí y de los otros tratan de reemplazarse en el nuevo capitalismo que se inventa en Estados Unidos, y 
que no es tanto un biopoder como un psicopoder (un soft power), por la formación de los comportamientos según las psicotécnicas de la "RM" apoyadas sobre las psicotecnologías puestas en obra por el mercadeo y hoy por la microeconomía de la gran distribución y la cognición de la atención.

Es así como en la sociedad de servicios, que se sitúa principalmente en la segunda mitad del siglo XX, se trata de reemplazar la administración (que es la institución de los programas escolares) por las industrias de programas, y de reemplazar las administraciones públicas en general (y las que constituyen la biopolítica en particular) por los consejos, las agencias privadas y los comités.

Es entonces el reino de lo que Anthony Giddens (1999) llama "el examen pericial". Este resulta del desarrollo de los "sistemas abstractos" (Giddens, 1999, pp. 89 y ss.) inducidos por la "distanciación espacio-temporal" (Giddens, 1999, pp. 25 y sucesivas), es decir, por la desterritorialización y por el hecho de que nuestras existencias están implicadas en redes tecnológicas de saberes especializados que se nos escapan inexorablemente y nos obligan a delegar la asunción el devenir a agencias que hacen de esta delegación mercados. En este contexto se despliega la economía de servicios que conduce a la disociación, es decir, a la destrucción de los medios asociados por el desarrollo de psicotecnologías que eliminan las facultades psíquicas y sociales, y en particular la atención, al reemplazarlas por autómatas sin procesos de reinteriorización, es decir, sin crítica y, por tanto, sin responsabilidad.

De todo ello resulta, sin embargo, el déficit atencional, la hiperactividad, la saturación cognitiva y afectiva, la infantilización de los adultos, la mayoración prematura de los menores y, a fin de cuentas, la desafección y la desafectación de lo que tiende a formar baldíos humanos y grupos comunitarios que reaccionan lanzándose muy violentamente en la regresión más arcaica; comenzando por Irán, a donde Foucault fue en 1979, escribió páginas perturbadoras y singularmente bellas, al mismo tiempo que malinterpretó totalmente la situación pues no veía nada distinto a un levantamiento de la sociedad contra el Estado (Foucault, 1994).

El desarrollo de este "examen de experto", por donde el biopoder de Estado retrocede ante el psicopoder del mercado, está en el origen también de lo que Giddens (1999) cree tener que describir como una integración reflexiva por la sociedad entera de los saberes de las ciencias sociales:

No se puede aplicar los descubrimientos de las ciencias sociales a un sujeto inerte; no podrían imponerse más que a través de su comprehensión por parte de los agentes sociales [...] Hay un va-i-ven entre el universo de la vida social y el saber sociológico, y en este proceso el saber sociológico se modela y remodela el universo social. (p. 24) 
Ahora bien, no es para nada evidente que se pueda hablar aquí de "reflexividad". Me parece que se trata mucho más de adaptación no-comprehensiva de los comportamientos a reglas socializadas en normas (lo que es una modalidad bien específica del proceso de adopción) en un contexto de disociación, si es verdad que la comprehensión es crítica (y por esto adulta) y forma la condición de un medio asociado que se ha vuelto un espacio crítico.

Sea lo que sea, los saberes de las ciencias sociales (de los que habla aquí Giddens) son salidos de lo que se forma a partir del desarrollo de las tecnologías de poder sobre los individuos, nos dice Foucault (1988), y es esto lo que dan una ciencias de los individuos con miras a una tecnología política: "No se podría aislar la aparición de la ciencia social de esta nueva racionalidad política ni esta nueva tecnología política" (p. 11).

A estos análisis del biopoder realizados en los años 1970 y recordados en 1982, Foucault precisa (1990), sin embargo, en esta conferencia que es necesario añadirles los de las técnicas de sí, y que su objeto final (encarado, como lo hemos visto, a través de su historia de la sexualidad) es la gubernamentalidad que pone en obra "cuatro grupos de técnicas: de producción, de sistemas de signos, de poder y de sí mismo", que rara vez están separadas. La gubernamentalidad es el "encuentro de las técnicas de dominación y de las técnicas de sí" (Foucault, 1990).

Evidentemente, se podría considerar que las psicotecnologías son este encuentro perfectamente realizado. Pero esto sería precisamente ignorar que la terapéutica no puede ser reducida a la biopolítica ${ }^{12}$. Y sería no comprender por qué Foucault regresa (precisamente en esta época) sobre la otra cuestión de la disciplina, introduciendo la épiméleia, cuya radical mélétè designa tardíamente la meditatio. Pero Bailly nos enseña que mélétè significa ante todo, precisamente, la disciplina (y en un sentido que no es precisamente el de las sociedades disciplinarias).

\section{Épiméleia y pharmakon}

Mélétè $(\mu \varepsilon \lambda \varepsilon \tau \eta)$ viene de mélétaô $(\mu \varepsilon \lambda \varepsilon \tau \alpha \omega)$. Este verbo polisémico significa ante todo poner cuidado a algo. Por lo mismo, designa el ejercicio en general de prepararse para algo y, en esto, una especie de entrenamiento. Por ejemplo, mientras Sócrates espera tomarse la cicuta, se prepara para la muerte por medio de esta disciplina que es su mélétè. Mélétéma $(\mu \varepsilon \lambda \varepsilon \tau \eta \mu \alpha)$ significa en esto primero el ejercicio práctico y, por extensión, designa el estudio. Es así como la mélétè termina por significar la meditatio.

Sin hablar de los efectos patológicos sobre los cuerpos mismos de esta biopolítica que escapó a los Estados, además de las cuestiones medioambientales en general como consecuencias de la incuria. 
El retorno operado por Foucault hacia las técnicas de sí desde la cuestión de las técnicas de dominación (o de poder) que forman (con la venida de la burguesía al poder) un biopoder, lo conducen igualmente a reexaminar la cuestión del entrenamiento (gymnasia) ya no como formación de un cuerpos social individualizado por la anatomopolítica con miras a su control, sino como individuación de un sí que está por naturaleza en exceso sobre un tal control. Es, pues, bien claro que al final de su vida y, de alguna forma, en pleno corazón de su tema, Foucault entra en el examen del otro sentido de la palabra disciplina, en el examen de su sentido antiguo: el que constituye y soporta la radical de épiméleai que significa, sin embargo, la administración.

La cuestión y la historia de la épiméleai deben entonces ser examinadas en dos contextos: la filosofía grecorromana y la espiritualidad cristiana. "Entre los griegos, estas prácticas [que son las técnicas de sí] tomarán la forma de un precepto: epimelesthai sautou, es decir: "el cuidado de sí", tener 'preocupación por sí', 'el sentirse preocupado, inquieto por sí'” (Foucault, 1990).

El precepto 'ocuparse de uno mismo' era, para los griegos, uno de los principales principios de la ciudad, [...] A nosotros, esta noción se nos ha vuelto ahora más bien oscura y desdibujada. Cuando se pregunta cuál es el principio moral más importante en la filosofía antigua, la respuesta inmediata no es 'cuidar de sí mismo', sino el principio délfico gnothi seauton ('conócete a ti mismo'). (Foucault, 1990, p. 50)

Este principio délfico fue, por lo demás, al comienzo una práctica, "una regla que había de ser observada para consultar el oráculo. 'Conócete a ti mismo' quería decir 'No supongas que eres un dios'" (Foucault, 1990, pp. 50-51).

Ahora bien, Foucault nos dice que la filosofía olvidó el primer principio de la épimelesthai sautou, del que el principio délfico era entonces un caso.

En los textos griegos y romanos, el mandamiento de conocerse a sí mismo está siempre asociado a ese otro principio que es el cuidado de sí. Ahora bien, su olvido comienza con la filosofía naciente —como lo testimonia el Alcibíades - donde Sócrates declara (nos dice Foucault) que enseñando a los hombres a ocuparse de ellos mismos les estaba enseñando a preocuparse por la ciudad (Foucault, 1990).

Es preciso subrayar, sin embargo, que en el Alcibíades, como siempre, Platón argumenta por la boca de Sócrates para la dialéctica y la anamnesis, es decir, para el pensamiento que piensa por sí mismo y que no recibe lecciones de los otros. Dicho de otro modo, argumenta contra la psicotécnica sofística, que es también una tecnología de poder.

Este mandamiento platónico de ocuparse de sí mismo para aprender a ocuparse de la ciudad, antes que ir a escuchar a sofistas que enseñan a cambio 
de retribución la logografía y el pithanon (el arte de persuadir), va contra ese uso psicotécnico del pharmakon. Y va de la par con la condena de la téchnē y, finalmente, con su denegación (de su papel constitutivo de toda anamnesis en tanto que hipomnesis) que está en el origen de la denegación por donde la filosofía se constituye, a fin de cuentas, en metafísica.

Por esto, hay razones históricas "que explican que el Conócete a ti mismo haya eclipsado el Pon cuidado de ti mismo" (Foucault, 1990), en particular el hecho de que con la moral cristiana como renuncia a sí mismo (bajo el peso de una moral de la culpabilidad, "los principios morales de la sociedad occidental han experimentado una transformación profunda" (Foucault, 1990) ${ }^{13}$. Esta es la orientación inicial de la filosofía como represión de la cuestión del pharmakon, y en particular de la escritura que pone en movimiento - como platonismo-ese mecanismo de ocultación inicial del principio que es el epimelesthai sautou en tanto que toma técnica del cuidado. Y es lo que subraya el propio Foucault: "tener cuidado de sí mismo consiste [en Alcibíades] a conocerse a sí mismo [...] El diálogo termina cuando Alcibíades comprende que él debe ponerse cuidado a sí mismo examinando su alma" (Foucault, 1990).

Lo que quiere decir que, con Platón, la épiméleia se volvió sinónimo de gnosis.

Si "hubo inversión de la jerarquía de los dos principios de la antigüedad" (Foucault, 1990), si los estoicos y los epicúreos han revalorizado las técnicas y la escritura de sí (como lo veremos), la cuestión que se plantea de entrada para Platón (que somete en realidad la épiméleia a la gnosis como somete la téchnē a la epistếmē) es la de la tecnicidad de las técnicas de sí. El gnôthy seauton significa que no es necesario pasar por las técnicas de los sofistas ni por las de la épiméleia cuando esta no está fundada en la anamnesis y la dialéctica que abre a la cuestión ¿ti esti? (¿qué es que?), que abre a la cuestión de lo que es: a la ontología.

Aquí, lo que en particular es denegado por Platón es la necesidad de pasar por la escritura, es decir, por el pharmakon, como lo hacen los sofistas y como lo harán precisamente los epicúreos y los estoicos. Es lo que mostrará La escritura de sí, que Foucault publicará un año después de la conferencia que articulaba el biopoder y las tecnologías políticas de los individuos con las técnicas de sí en la cuestión de la gubernamentalidad (Foucault, 1990). Un año antes, en Las técnicas de sí, él subraya que el período helenístico ve un renacimiento del cultivo de sí donde la escritura toma una nueva importancia:

Y hay para esto una segunda razón: "en la filosofía teórica que va de Descartes a Husserl, el conocimiento de sí (el sujeto pensante) ha tomado una importancia cada vez más grande en tanto que primer jalón de la teoría del saber". 
Tomará notas sobre sí mismo, que se podrán releer [...] reactivar para sí las verdades de las que se ha tenido necesidad [...] el desarrollo de las estructuras administrativas bajo el imperio aumentará el número de los escritos y la importancia de la escritura en la esfera política. [Después de Platón] con el período helenístico [...] la dialéctica [salida del diálogo] encuentra su terreno de expresión en la correspondencia. Tener cuidado consigo mismo de acá en adelante va a la par con una actividad de escritura constante. El sí mismo es algo sobre lo cual hay materia para escribir. El acto de escribir intensifica y profundiza la experiencia de sí. (Foucault, 1990)

Estas psicotécnicas —técnicas del alma- que también se acompañan de somato-técnicas -esos casos de técnicas del cuerpo (en el sentido en que habla más generalmente Mauss), por ejemplo, como deambulatio y gymnasia-. Esas psicotécnicas, como mélétè entendida en el sentido de meditatio, son procesos de concentración sobre un objeto de contemplación ${ }^{14}$ que prefiguran la confesión, de la misma manera como el arte de escuchar y la escucha de sí prefiguran el examen de conciencia (Foucault, 1990). Este examen de conciencia pronto será prescrito por un director de conciencia, para no decir dictado por él, lo que Kant, con la aufklärung, viniendo después de Martín Lutero e Ignacio de Loyola, condenará como factor de minoridad. En este sentido, afirma que la escritura y la lectura forman ese proceso histórico por donde se forma la mayoridad en tanto que conciencia racional, es decir, crítica.

\section{Psicopoder, gramatización y cristiandad}

Anacoresis, askésis, mélétè sostenida por la práctica de las hypomnémata, mnemotécnicas en general, gymnasia incluso, definida como lucha contra la tentación en el sentido de los estoicos; con el cristianismo, todas las técnicas de sí son reinscritas en el cuadro de una institucionalización religiosa de las prácticas psicotécnicas, donde la askésis es redefinida como penitencia y donde "lo que era privado para los estoicos se vuelve público para los cristianos" (Foucault, 1990).

Desde Casiano, el cristianismo utilizará técnicas de verbalización que, a partir del siglo XVIII, y luego con las ciencias humanas y con el psicoanálisis, ya no son "el instrumento de la renuncia del sujeto [...] sino [...] el instrumento positivo de la constitución de un nuevo sujeto" (Foucault, 1990).

En esta historia eclesial y occidental de las técnicas de sí, "conglomerado heredado" (Dodds, 1980) desde el cual Loyola redactará sus Ejercicios espirituales, Foucault permanece extrañamente silencioso en cuanto a lo que ocurre, precisamente, primero con Erasmo y Lutero y luego con Loyola. Sin embargo, ellos están

14 Como este será el caso con el monaquismo (Foucault, 1990). En la vida del monje, "la contemplación constituye el bien supremo". Todo es asunto de concentración y de atención, "para Casiano, la movilidad constante del espíritu significa su debilidad. Ella es lo que distrae al individuo de la contemplación de Dios". Se trata "de inmovilizar la conciencia [...] de eliminar los movimientos del espíritu que alejan de Dios" (Foucault, 1990). 
en el origen de los establecimientos o de las prescripciones de enseñanzas que han interesado tanto a Foucault en Vigilar y castigar. Asimismo, él no dice nada sobre la imprenta, sin la cual el protestantismo (condición de la Contra-Reforma) no hubiera sido posible nunca.

Port-Royal, su lógica y su gramática, están en 1966 en el corazón de los análisis de la constitución de la epistếmē clásica en Las palabras y las cosas. En la época clásica, "el comentario deja su lugar a la crítica [que] se opone al comentario como el análisis de una forma visible al descubrimiento de un contenido oculto" (Foucault, 1968, p. 85).

\section{Este devenir supone un análisis del lenguaje mismo y busca}

constituir el tesoro de una lengua perfectamente analítica. Se manifiesta también en el orden gramatical como un análisis de los valores representativos de la sintaxis, del orden de las palabras, de la construcción de las frases [...] La crítica se da también su espacio en el examen de las formas de la retórica. (Foucault, 1968, p. 85)

En esta experiencia nueva del lenguaje se coloca la cuestión de la representación, donde "un lenguaje no puede representar al pensamiento, de golpe, en su totalidad; es necesario que lo disponga parte a parte según un orden lineal" (Foucault, 1968, p. 87).

Por ello, la gramática general va a condicionar la formación del pensamiento clásico:

La gramática general es el estudio del orden verbal en su relación con la simultaneidad que está encargado de representar. Así pues no tiene como objeto propio ni al pensamiento ni al lenguaje, sino al discurso, entendido como sucesión de signos verbales. (Foucault, 1968, p. 88, cursivas del autor)

Y es también por esta gramática por la que se forma la cuestión clásica de la universalidad: "La gramática como reflexión sobre el lenguaje en general, manifiesta la relación que éste tiene con la universalidad [...]. La lengua universal no restablece el orden de las épocas pasadas; inventa signos" (Foucault, 1968, pp. 89-90).

Ahora bien, a pesar de todo lo que Foucault dirá en la misma obra sobre el lugar de la escritura y de la reflexión sobre ella a partir de la teoría de la derivación (Foucault, 1968, pp. 115 y ss.), la formación de estas "regularidades discursivas" no parece que le debiera nada (a sus ojos) a la gramatización, cuya intensificación constante describe Sylvain Auroux (1993) a partir de fines del Imperio romano que soporta y condiciona "el desarrollo de los saberes lingüísticos europeos" (p. 71). Asimismo, conduce a la impresión industrial del periódico diario y luego a lo que Auroux (1993) describe como una tercera revolución tecnológica 
de la gramatización que nosotros mismos vivimos a través de la informática y el desarrollo de las "industrias de la lengua".

Auroux (1993) muestra magistralmente que el desarrollo de los saberes lingüísticos es de las tecnologías lingüísticas a través de las cuales se forma un poder lingüístico. Sin el desarrollo de estas tecnologías y especialmente de los caracteres móviles que plantearán, por ejemplo, la cuestión de la normalización ortográfica y, por tanto, sintáctica, pero también de la traducción y de la semántica; las cuestiones de la linealidad del discurso, la gramática general y la lengua universal nunca hubieran podido formarse ni seguramente conducir a la instrucción pública obligatoria. Y Auroux (1993) muestra que estas son esencialmente tanto tecnologías de poder como tecnologías de saber ${ }^{15}$.

La gramatización como imprenta viene a realizar un proceso que toma sus fuentes a fines del Imperio romano (Stiegler, 2006) y el propio Foucault remarca en 1982 la importancia que ha tomado la escritura a través de las estructuras administrativas en la antigüedad imperial:

De la época tardo-antigua (siglo $\mathrm{V}$ de nuestra era) hasta comienzos del siglo XIX [...] vemos que se produce un proceso único en su género: la gramatización masiva, a partir de una sola tradición lingüística inicial (la tradición greco-latina), de las lenguas del mundo. Esta gramatización constituye, después del advenimiento de la escritura [en las edades proto-históricas y antiguas] [...] la segunda revolución tecnolingüística. Aunque la empresa de gramatización sea de hecho casi infinita [...] se la puede considerar como prácticamente acabada en la actualidad. (Auroux, 1993, p. 71)

La empresa de gramatización es la operación indisociablemente espiritual y tecnológica de formalización lingüística de los idiomas. Auroux (1993) muestra que la imprenta está intrínsecamente ligada a la colonización como exportación del cristianismo a través de la tecnología del libro impreso.

Lo que le había permitido a Lutero entrar en luchas contra la dominación del Vaticano es vuelto a poner así a su servicio por medio de las prácticas espirituales de Loyola que, como Ejercicios (1987), fundan la orden de la Compañía de Jesús y la institución escolar que él forma a través de las misiones. Es a la vez via la Reforma, via la Contrarreforma y via la crítica (por la Ilustración) de la minoridad que imponen los "directores de conciencia"16, como se forma el espacio de escritura crítica y sabia para el público que lee.

Ahora bien, esto se acompaña de una teoría y práctica gramaticales que reposan sobre lo que Auroux (1993) llama la "gramática latina extendida". Esta es la base histórica de lo que Foucault analizaba en 1966 como gramática general,

\footnotetext{
15 Ver particularmente su comentario de la política castellana de la lengua en 1492 (Foucault, 1993, p. 93).

16 Ver Kant ¿Qué es la ilustración? y mi comentario en el capítulo 1.8 (Stiegler, 2006).
} 
pensamiento clásico de la representación y órdenes de la mathesis y de la taxonomía (Foucault, 1968, p. 77 y ss.) que soporta el cuadro (Foucault, 1968, p. 78). La formación de la gramática latina extendida (muy próximo de lo que Derrida [1996] hubiera descrito como una "mundialatinización" [p. 58]) está ligada a una transformación de la situación escolar:

Los niños griegos o latinos que frecuentaban la escuela del gramático sabían ya su lengua; el estudio de la gramática sólo era una etapa en el acceso a la cultura escrita. Para un europeo del siglo IX, el latín era ante todo una lengua secundaria que le era preciso aprender. La gramática latina existe; va a volverse prioritariamente una técnica de aprendizaje de la lengua. (Auroux, 1993, p. 81)

Es sobre esta base, formada en la larga duración del período de gramatización de las vernáculas que comienza en el siglo $\mathrm{V}$, cuando la gramática latina extendida va a generalizarse, mundializarse y a emprender la gramatización de todos los idiomas. Asimismo, nuevas tecnologías del espíritu (y aquí, del Espíritu Santo) se harán posibles por la imprenta y constituirán las herramientas lingüísticas, que son las gramáticas, en tanto que manuales, y los diccionarios (Auroux, 1993, p. 109), por donde la letra del libro que es la Biblia se vuelve accesible a todos los pueblos colonizados. Con ella, ese sistema de cuidado llamado cristiandad, que transforma al mismo tiempo e institucionaliza las técnicas de sí de la épiméleia.

Pero esto solo es posible desde el "fondo latino" de esta cultura lingüística a la letra. Ahora bien, es también lo que constituye la condición de posibilidad de la gramática general, que está en el corazón de la teoría de la epistếmē clásica descrita por Las palabras y las cosas:

El fondo latino constituye un factor de unificación teórica que no tiene equivalente en la historia de las ciencias del lenguaje. Él sólo explica la homogeneidad conceptual de esas disciplinas, lo que se puede considerar como su identidad de metalenguaje [...] Sin la tradición gramatical latina (esencialmente Donato, que fue el maestro de San Jerónimo, el traductor de la Biblia al latín y Prisciano, muchos más complejo...) no habría habido simplemente lo que hoy llamamos la lingüística. (Auroux, 1993, pp. 82, 85)

En cuanto a la gramática general, que ciertamente no es la lingüística pero que es un paso hacia ella, supone tener en cuenta tres elementos históricos fundamentales:

la refundición de la gramática latina, la imprenta y los grandes descubrimiento $\mathrm{s}^{17}$ [...] Gramatización e imprenta hacen parte de la misma revolución tecno-lingüística [...] La práctica manuscrita medieval deja lugar [...] en cada ejemplar, a la variabilidad,

Auroux (1993) precisa que "hay una intrincación cronológica compleja entre todos esos elementos (con una ligera ventaja para la refundición de los estudios latinos y la imprenta), aunque está por fuera de discusión la cuestión de establecer una causalidad lineal entre ellos" (p. 95). 
especialmente ortográfica. Con la imprenta, no solamente la multiplicación de lo mismo es inevitable, sino la normalización de los vernáculos se vuelve un asunto de estándar profesional. La ortografía, la puntuación y la regularización de la morfología conciernen a los impresores tipógrafos [...] La difusión del libro impreso impone, entonces, la constitución de un espacio ilimitado en el cual cada idioma, desembarazado de la variación geográfica, se volvió isótopo. (Auroux, pp. 95, 97)

La normalización, que se volvió después de Georges Canguilhem un objeto de pensamiento importante, y singularmente importante en la obra de Foucault (Stiegler, 2006) ${ }^{18}$, procede fundamentalmente de la gramatización. Y es claro que la alfabetización tendrá consecuencias considerables en materia de disciplina tecnolingüística y, por ello, de formación de la atención lingüística, literaria y lógica como capacidad de discernir las partes del discurso en el flujo de la conciencia simbolizadora idiomáticamente ${ }^{19}$, es decir, singularmente como consciencia de mayor de edad.

La formación y el control de esta disciplina del discurso será el objeto de una verdadera competencia entre los diversos poderes espirituales. En este contexto, se desarrolla la gramática general. El espacio ilimitado formado por la gramatización es donde cada idioma tiende a devenir isótopo; es un espacio crítico y también el de un combate ${ }^{20}$. La cuestión de las Luces es una época singularmente dinámica y decisiva de este combate: la formación de la conciencia crítica y de adulto supone la de esta atención lógica salida de la gramatización del discurso. Ahora bien, no se encuentra huella de este combate en la teorización foucaultiana de las tecnologías de poder, que son también las tecnologías del saber. Claramente, el asunto aquí es: ¿cómo la tecnología, que siempre es el basamento de toda "batalla de la inteligencia", anuda contradictoriamente el saber con el poder y recíprocamente?

Para quien se ha asomado a la historia de la imprenta, y antes de ella a la de los scriptoria o de la biblioteca de Alejandría ${ }^{21}$, los pasajes que evocan el libro en La Arqueología del saber son decepcionantes. Ese dispositivo de retención no es pensado aquí con precisión ni desde su tecnicidad material ni su tecnicidad intelectual de producción, tal como ella está ligada precisamente de forma estrecha a la constitución de lo que Auroux llama las herramientas lingüísticas (Foucault, 1970a, pp. 36-37). Y esto sorprende retrospectivamente

18 Ver particularmente el capítulo 7.36.

19 Es idiomática toda diacronización de la lengua que se constituya en un discurso que tienda a transindividuar esa lengua, eventualmente como lengua de especialidad y de disciplina. El idioma no es necesariamente un dialecto. Y, en español, él da su nombre a la lengua misma.

20 Volveré sobre este tema en La técnica y el tiempo 5. La guerra de los espíritus, que aparecerá en ediciones Galileo [Éditions Galilée] (Stiegler, 2005).

21 Ver tomos I y II de Des Alexandries bajo la dirección de Christian Jacobs (2002, 2003). 
al lector que conoce la atención que Foucault le pondrá luego a la literalidad de las técnicas de sí. Además (y esto es algo más sorprendente aún), la insistencia de La arqueología del saber en la materialidad documental (Foucault, 1970a, p. 17) habría permitido pensar que esa historia material del libro debía ser el objeto de un estudio específico.

Tampoco hay nada en esta obra sobre el lugar de la república de las letras en el advenimiento de la burguesía que, sin embargo, es paralelo al desarrollo de un escrito que ya no es el de los Imperios helénico y romano desde hace mucho tiempo, sino del que conduce a la sociedad industrial. Ahora bien, esta es un nuevo estadio de la gramatización claramente más allá de las formaciones discursivas que suponen esas Luces sin las cuales James Watt nunca hubiera encontrado a Matthieu Boulton ${ }^{22}$. Y en esto, la gramatización constituye un dispositivo completamente extraordinario en la historia humana entre el logos y su otro; pero del que La arqueología del saber no dice nada, mientras que incluso la cuestión de las relaciones entre lo discursivo y lo no-discursivo es en el fondo su principal objeto.

\section{Referencias}

Aglieta, M. (2007, 1 de septiembre). Le capitalisme, de bulle en bulle [entrevista]. Le Monde. https://bit.ly/3jV4loJ

Auroux, S. (1993). La révolution technologique de la grammatisation. Mardaga.

Bernays, E. (2007). Propaganda. La Découverte.

De Loyola, I. (1987). Ejercicios espirituales (S. Dalmases, ed.). Sal Terrae.

Derrida, J. (1996). Foi et savoir. Les deux sources de la "religion" aux limites de la simple raison». En J. Derrida y G. Vattimo (dirs.), La religion (pp. 9-86). Seuil.

Dodds, E. (1980). Los griegos y lo irracional. Alianza.

Foucault, M. (1966). El nacimiento de la clínica: una arqueología de la mirada médica. Siglo XXI.

Foucault, M. (1994). Dits et écrits. Gallimard.

Foucault, M. (1968). Las palabras y las cosas. Siglo XXI.

Foucault, M. (1970a). La Arqueología del saber. Siglo XXI.

22 Ver Bertrand Gille (1978, p. 70).

- 282 Ciencios Sociales y Educación, 10 (20) • Julio-Diciembre 2021 • pp. 263-284 • ISSN (en línea): 2590-7344 
Foucault, M. (1970b). Naissance de la clinique: Une archeologie du regard medical. PUF.

Foucault, M. (1983). L'écriture de soi. Corps Écrit. “L'autoportrait”, (5). PUF.

Foucault, M. (1988). Technologies of the Self: A Seminar with Michel Foucault. University of Massachusetts Press.

Foucault, M. (1990a). Tecnologías del yo y otros textos afines. Paidós.

Foucault, M. (1990b). La vida de los hombres infames: ensayos sobre desviación y dominación. La Piqueta.

Foucault, M. (1999). Las mallas del poder. En M. Foucault, Estética, ética y hermenéutica. Obras Esenciales. Volumen III (pp. 235-254). Paidós.

Foucault, M. (2007). Historia de la sexualidad 1: la Voluntad de saber. Siglo XXI.

Giddens, A. (1999). Consecuencias de la modernidad. Alianza.

Gille, B. (1978). Histoire des techniques. Gallimard, La Pléiade.

Jacobs, C. (dir.). (2002). Des Alexandries I. Du livre au texte. BNF Éditions.

Jacobs, C. (dir.). (2003). Des Alexandries II. Les métamorphoses du lecteur. BNF Éditions.

Kintlzer, C. (1987). Condorcet: l'instruction publique et la naissance de citoyen. Gallimard.

Marcuse, H. (2002). Eros y civilización. Ariel.

Packard, V. (1958). La persuasion clandestine. Calmann-Levy.

Sarkozy, N. (2007, 4 de septiembre). Lettre aux Educateurs. Présidence de la République. https://bit.ly/3wlrDXn

Simondon, G. (2008). El modo de existencia de los objetos técnicos. Prometeo.

Stiegler, B. (2004). De la misère symbolique 1. L'époque hyperindustrielle. Éditions Galilée.

Stiegler, B. (2005). La Technique et le Temps 3. Éditions Galilée.

Stiegler, B. (2006). La télécracie contre la démocratie. Lettre ouverte aux représentants politiques. Flammarion. 
Stiegler, B. (2006a). Mécréance et discrédit. 3. L’esprit perdu du capitalisme. Galilée.

Stiegler, B. (2006b). Réenchanter le monde: la valeur esprit contre le populisme industriel. Flammarion.

Stiegler, B. (2008). Prendre soin - 1. De la jeunesse et des générations. Flammarion. 